\title{
Integrated interpretation of pXRF data on ancient nephrite artifacts excavated from Tomb No.1 in Yuehe Town, Henan Province, China
}

\author{
Dian Chen ${ }^{1,2}$, Yimin Yang ${ }^{1,2}$, Baotong Qiao ${ }^{3}$, Jingpu Li ${ }^{1,2}$ and Wugan Luo ${ }^{1,2^{*}}$ (D)
}

\begin{abstract}
Previous studies of ancient jade using portable X-ray fluorescence (pXRF) have mostly focused on mineral identification, alteration status and provenance determination. It is usually used as an auxiliary instrument for spectroscopic detection with finer resolution. However, there is no substitute for the efficiency and stability of pXRF in-situ nondestructive analysis, which is less affected by the test environment. The scale of the data from the pXRF analysis did not allow for a more in-depth interpretation of ancient jade in the past. In this study, pXRF has been carried out for a total of 112 pieces of nephrite artifacts unearthed from the Yuehe tomb No.1 in Nanyang City, Henan Province, Central China. Certain patterns become clearer as the size of the data increases. The coefficient of variation, cluster analysis and correlation analysis can be used to separate elements into different assemblages, revealing whether the elements are from the primary and impurity minerals of nephrite itself, from the burial microenvironment in the soil, or even from other specific sources. In addition, most of the secondary whitening occurring in the batch of nephrite are accompanied by an increase in Ca content, confirming the previously refuted theory of calcification. More importantly, the principal component analysis of the twin nephrite artifacts suggests visually indistinguishable elemental changes caused by secondary changes, which may lead to misjudgment of ancient nephrite provenance using elemental data.
\end{abstract}

Keywords: Jade, Nephrite, pXRF, Non-destructive analysis, Statistical analysis

\section{Introduction}

Jade culture is a material culture unique to Chinese civilization, and exploring the process of the emergence and development of the civilization through jade culture has been an important area of archaeological research [1]. The so-called jade, however, has been discussed for decades before the academic circle has clarified the concept and reached a certain consensus [2]. The so-called concept of 'jade' has both narrow and broad senses. Jade in

\footnotetext{
*Correspondence: xiahua@ucas.edu.cn

1 Department of Archaeology and Anthropology, University of Chinese

Academy of Sciences, Beijing 100049, China

Full list of author information is available at the end of the article
}

the wide sense is actually the good-looking stone, especially in some ancient texts, where it was hard to distinguish between similar minerals at all due to the weak identification skills of people at that time. While in the specific sense, a commonly accepted modern concept, there are only two types of jade, one is nephrite and the other is jadeite. The reason why the two stand out from the many beautiful stones is that they have excellent qualities in terms of color, transparency, luster, clarity, toughness, structure, hardness, and specific gravity, etc. But the use of jadeite in China was not until the mid to late Qing Dynasty (1636-1912 AD) when it began to gradually become popular [3]. So the truth is that the nephrite with a history of around 9000 years of use in China, is the
Springer Open

(c) The Author(s) 2022. Open Access This article is licensed under a Creative Commons Attribution 4.0 International License, which permits use, sharing, adaptation, distribution and reproduction in any medium or format, as long as you give appropriate credit to the original author(s) and the source, provide a link to the Creative Commons licence, and indicate if changes were made. The images or other third party material in this article are included in the article's Creative Commons licence, unless indicated otherwise in a credit line to the material. If material is not included in the article's Creative Commons licence and your intended use is not permitted by statutory regulation or exceeds the permitted use, you will need to obtain permission directly from the copyright holder. To view a copy of this licence, visit http://creativecommons.org/licenses/by/4.0/. The Creative Commons Public Domain Dedication waiver (http://creativeco mmons.org/publicdomain/zero/1.0/) applies to the data made available in this article, unless otherwise stated in a credit line to the data. 
representative and even core of jade culture [4]. Besides, nephrite has also been treasured since prehistoric times in different cultures, e.g., in Italy, Switzerland, Russia, Bulgaria, Hungary, Mongolia, Japan, Pakistan, Philippines, Malaysia, Vietnam, Thailand, Cambodia, Australia, New Zealand and so on [4-6].

The composition of nephrite is close to the monomineralic represented by the minerals of isomorphic tremolite-ferroactinolite series, so it can be composed either of iron-rich (actinolite) or magnesium-rich (tremolite) varieties with average chemical formula $\mathrm{Ca}_{2}(\mathrm{Mg}, \mathrm{Fe})_{5}\left[\mathrm{Si}_{8} \mathrm{O}_{22}\right]$ $(\mathrm{OH})_{2}$ [7]. Nephrite varies in color mainly depending on iron and chromium content as well as some admixtures of other minerals such as serpentine, chlorite, calcite, magnesite, talc, actinolite, and graphite et al. [8-10]. The dependence of the contents of the basic formula and impurity elements in nephrite elemental composition has been the subject of a number of studies in recent decades [9]. With this trend, plenty of past studies focused on the elemental analysis of antique nephrite were mainly for the purpose of providing information for relics conservation and for tracking or discriminating the provenance [5, $11,12]$. Analytical methods used for chemical characterization of archaeological nephrite artifacts are required to be non-destructive. As a result, X-ray fluorescence (XRF) spectrometry and some innovative techniques such as PIXE are most popular [13-15].

However, when faced with large quantities of archaeological nephrite for in situ testing and the restrictions imposed by various regulations, only portable instruments are allowed, among which portable X-ray fluorescence (pXRF) is undoubtedly the most suitable choice. Although it has been criticized for often being relatively rough than laboratory equipment in terms of data [16], its usefulness cannot be underestimated, especially when the number of nephrite measured is on a larger scale, and the comparison of data from the same batch appears to have considerable potential for research value, especially as it can also be combined with cultural, typological, stylistic and other factors to uncover fuller archaeological information.

With the generous support of the Institute of Cultural Relic Research of Nanyang City, we were able to conduct a survey of 112 nephrite artifacts unearthed from the Tomb No.1, Yuehe Town, Tongbai [17]. The analysis of this huge number is quite large-scale, and can be an example of pXRF applied to the study of ancient jade.

\section{Archaeological background}

\section{Burial context}

The Tomb No.1, Yuehe Town, Tongbai County was excavated in the early 1990s. A total of 29 pieces of bronze, 746 pieces of jade and stone, and 4 pieces of wood and lacquer were found. The inscriptions on one bronze musical instrument indicate that the tomb occupier was the ruler of the Yang state $[14,15]$. Based on the burial specification as well as the style and decoration of the unearthed artifacts, this tomb is dated to the late Spring and Autumn period [18].

Tongbai County is located in Nanyang City, the southwest of Henan province, bordering Hubei province to the south (Fig. 1). Tongbai is the watershed between the two basins of the Yangtze River and the Huai River, and it is also the birthplace of the Huai River. From the Neolithic Age to the Zhou Dynasty, the southwestern region of Henan has been a zone of contention between the political power of the north and the south [17]. Tongbai was one of the important areas of the southward expansion of the Western Zhou Dynasty (1045-771 BCE), and the Yang state was established there. In the Spring and Autumn Period (770-476 BCE), the vassal states in Nanyang Basin were successively defeated by the state of $\mathrm{Chu}$, after that the Yang state reduced to a subordinate [19].

The Zuo Zhuan, a commentary on the ancient Chinese chronicle Spring and Autumn Annals, recorded that in the thirtieth year of Duke Zhao's reign (512 BCE), King Zhao of Chu had granted the former land of the Yang state to two Princes of $\mathrm{Wu}$, which is evidence that Yang had already perished before then. After the fall of the state, the Yang people became accommodated into Chu. For example, during the Spring and Autumn period and the Warring States period, there was a Yang clan among the nobles of the state of Chu, and a typical representative of this clan was Yang Youji, a great general who was known for his skill in archery [20].

\section{Jade culture in the Spring and Autumn period}

The Spring and Autumn and Warring States periods witnessed a great emancipation in the history of Chinese thought. The jade culture before the Three Dynasties (Xia, Shang and Zhou) still had a clear shamanistic element, but during this period the enlightenment of the sages and philosophers transcended the worship of the gods, and the 'divine' qualities of jade gradually faded away, carrying a fundamental change in connotation. Jade was incorporated into the ritual system and given a moral conception [21].

A small number of jade artifacts from the Spring and Autumn period were found at sites where ceremony or covenant were performed, while the majority were unearthed from high-grade tombs, indicating that jade artifacts of this time were almost always the exclusive possession of the ruling class. It is impressive that the nobility valued jades highly in the Spring and Autumn Period, not only for its aesthetic beauty but also for the social value it represented. Confucius (551-479 BCE) 


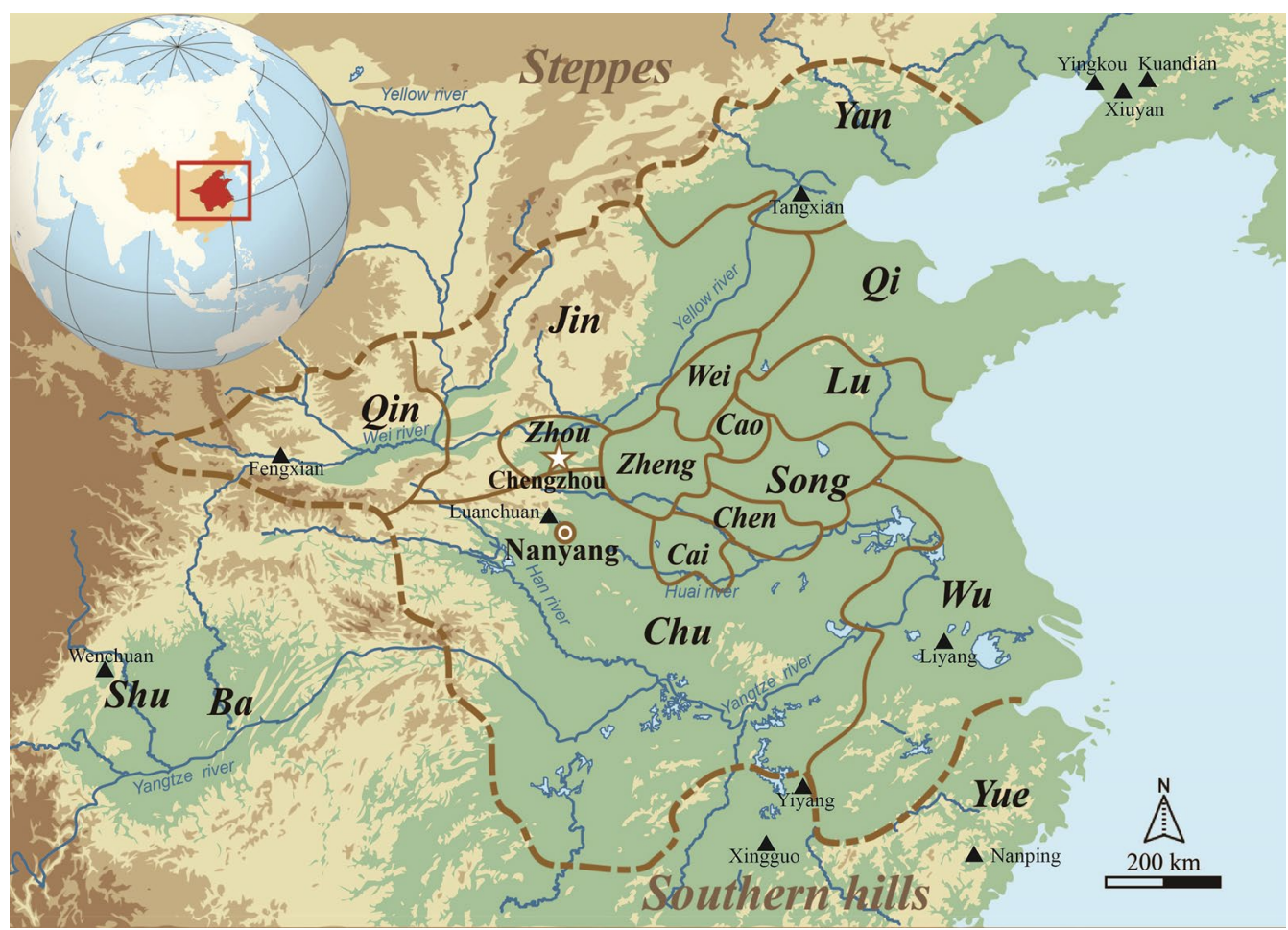

Fig. 1 Location of the major nephrite deposits in the Central Plain (solid black triangle) and distribution of States in the late Spring and Autumn period (around fifth century BC)

was quoted as saying 'A gentleman never leaves jade except for some sufficient reason', as a symbol of class and as a reminder of the virtues to a gentleman, for these virtues are embedded in jade. According to Shuo Wen, compiled by Xu Shen of the Eastern Han (25-220 $\mathrm{AD})$, the five virtues of jade were benevolence, integrity, intelligence, bravery and trustworthiness, which were exactly those expected of a gentleman [22].

Most importantly, there are six auspicious jade implements that were dedicated for ritual ceremonies in Zhou Rites: Bi-disk (donut-shaped discs) for Heaven, Cong (squared tubes with a round hollows) for Earth, Gui (pointed tablet) for East, Zhang (forked sword) for South, Tiger for West, Huang (crescents) for North. In addition, the ideology of 'treating death as rebirth' was popular at that time, which led to the establishment of a grand and complete funeral system and a unique jade culture. It was believed that jade was the essence of heaven and earth, and that jade could nourish the body and was a medium for communicating with the gods and ghosts, making the spirit and the soul immortal [21]. Correspondingly, the jade used for funerals would be placed in different parts of the deceased that Bi-disk at back, Cong at belly, Gui at left, Tiger at right, Zhang at head and Huang at foot [23].

\section{The jade in Yuehe Tomb No.1}

The jade in Yuehe Tomb No.1 are in sets that largely observed the rituals (Fig. 2). However, the jade artifact designated as Cong is not of the typical square outside and round inside shape, but rather is round and plain without decoration [17]. The reasons for this simplification or substitute are not clear and may be related to the context of the gradual propriety disintegration in the late Spring and Autumn period [17, 24]. After the middle of the Spring and Autumn period, kingship declined, vassals and lords rose together, and political turmoil ensued. Qin in the west, Qi in the east, Jin in the north, Chu in the south, and Wu and Yue in the southeast all grew to become powerful states. As a result of this situation, jade was also developed in a variety of ways. In general, jade from Qin has simple form, hard lines, decorative geometric shapes with shallow shaded lines; jade from the Central Plains region is popularly decorated with double shaded lines; jade from Chu has very compact pattern with densely lines and is primed for a gorgeous and elaborate style [1].

As for Yuehe jade, most of them are closer in shape, style and decoration to the Central Plains jade artifacts (all pictures and descriptions are listed in Additional file 1: Table S1). However, there also exist some jade 


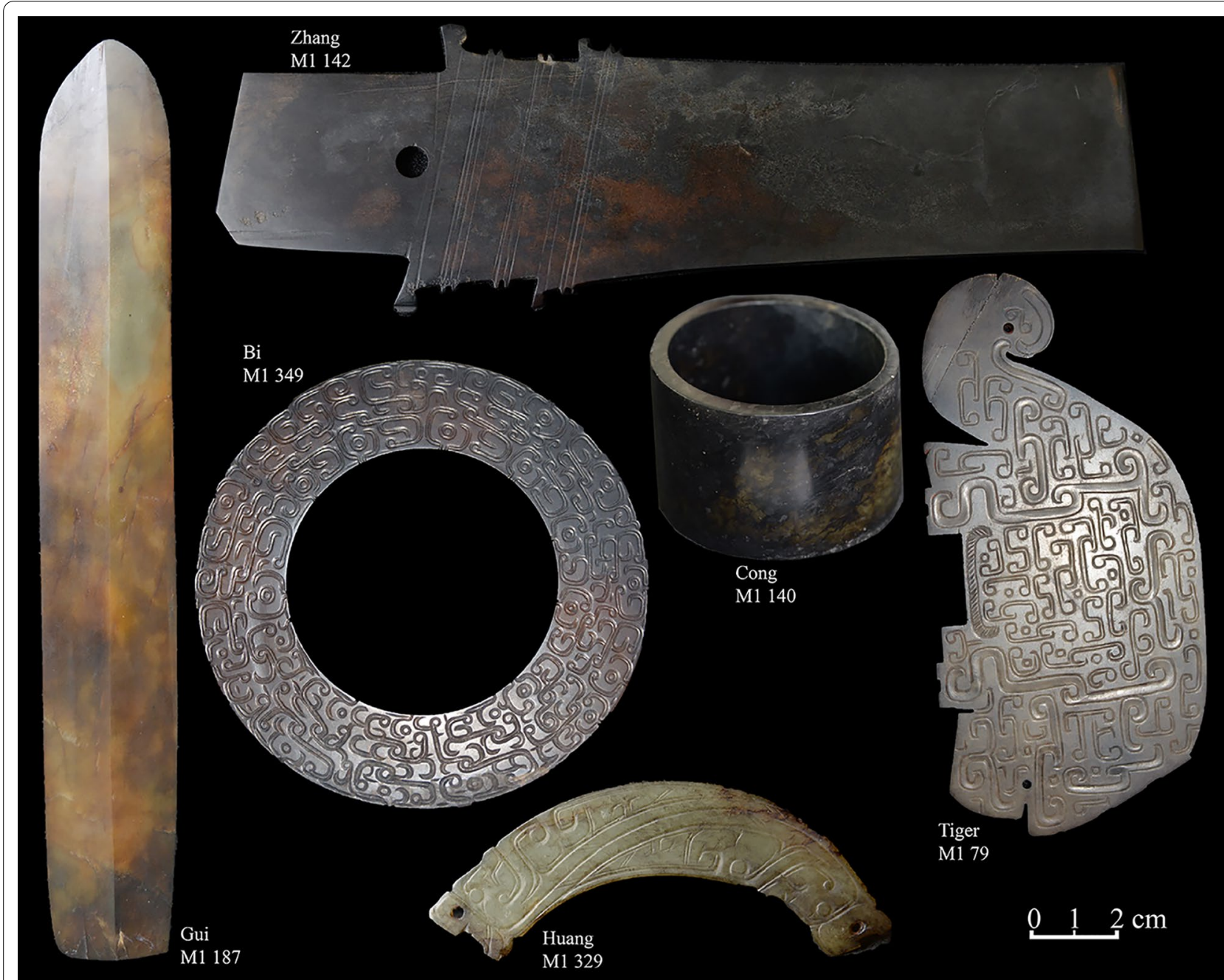

Fig. 2 The six auspicious jade implements from Yuehe Tomb No.1

pieces with the characteristics of other regions, roughly divided into several types of $\mathrm{Chu}, \mathrm{Wu}$, Yue and Dongyi styles, fully reflecting the exchange and integration of cultures [25].

The Yuehe Tomb No. 1 dates before the destruction of the Yang state, when the power of Chu expanded northward and probably have approached to the Yang state. The culture of Yang was naturally influenced by it. For instance, the decorative twisted silk motifs, which were very popular in Chu, appear on the oblong jade pedants M1:100 and M1:318, and the jade hilt M1:136 [25] (Fig. 3). The main features of Wu style jade are the fat decoration, the flat and convex relief, the tight pattern, and the delicate carving. For example, the oblong jade ornaments M1:129 and M1:164 (Fig. 3) are decorated on both sides with shallow relief carvings of dragon heads, the details of which are intricately carved in shade to show rounded eyes and open mouths and tongues. The remarkable feature of Yue style jade is the crown-shaped projection decorated on the outer edge. M1:265 and M1:399 are a pair of jade Jue with five projections, while M1:165 jade ring equips with four projections [25]. It is speculated that this particular component may have been associated with the worship of the sun and moon [26]. The Dongyi were a much earlier tribe that operated in the general area of Qi and Lu (Fig. 1), and this culture is best characterized by the unique bird element. M1:78 and M1:259 are a pair of very similar jade pendants in the shape of Huang, that can be considered representative of the Dongyi style. The overall design is that of a phoenix bird, with obvious elements such as drooping heads, arched backs, drooping tails, and hooked beaks, which should be closely related to the cult of the phoenix bird [25].

In reality, the Yang state was rather weak and seemed not to have the status of receiving polite receptions and 


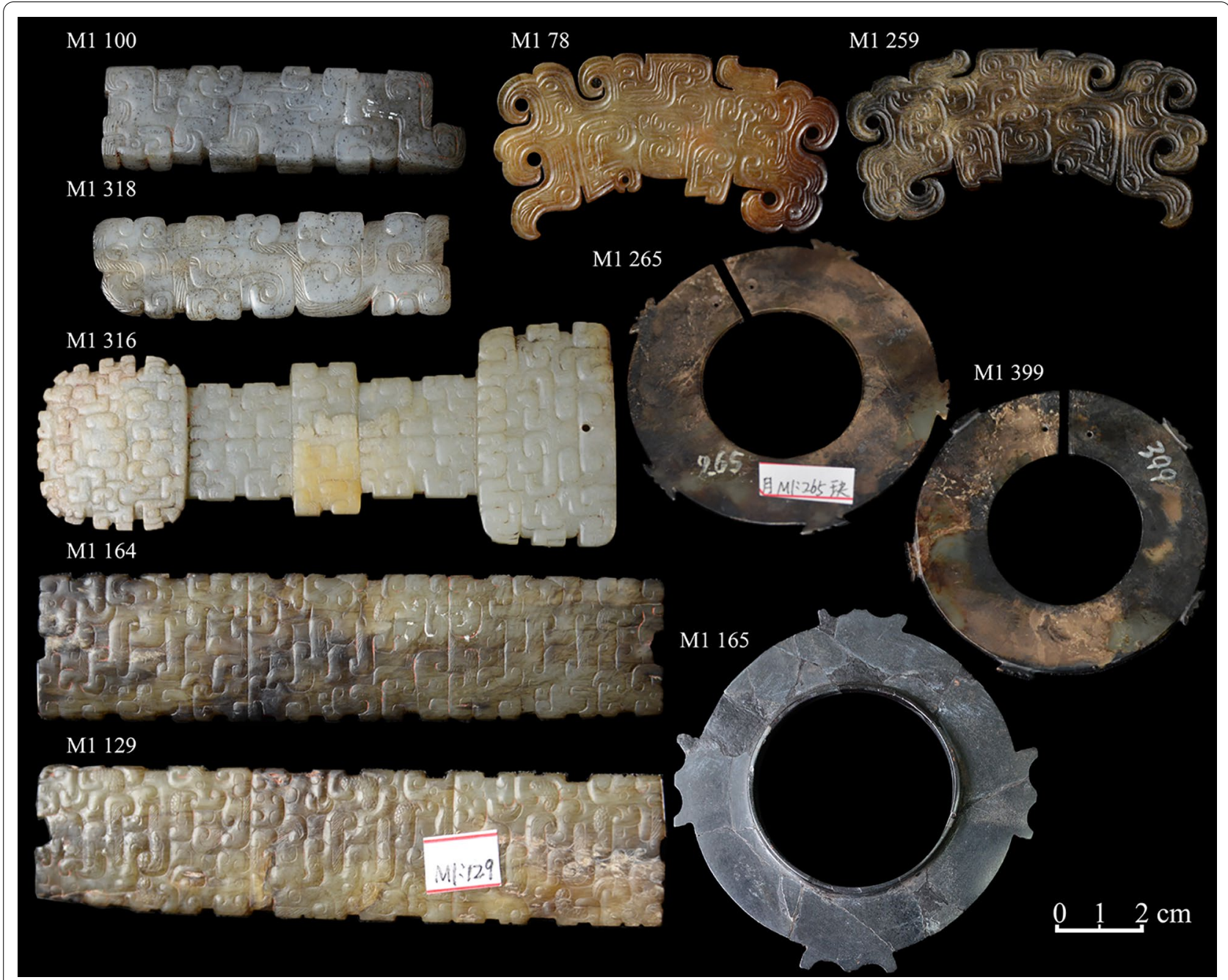

Fig. 3 Typical jade objects of different regional styles from Yuehe Tomb No.1

rewards from the central authority. These jade artifacts may have been gifts in the process of reciprocity or as payments in kind between the Yang state and other vassal states [24]. It is also possible that they were presents from neighboring vassal states to assist in the burial of the ruler of the Yang state [24].

\section{Methods}

Elemental analysis was conducted using a Thermo Niton XL3t 950 GOLDD + portable X-ray fluorescence spectrometer with a silver $(\mathrm{Ag})$ anode tube, geometrically optimized large area Si-drift detector and protective ultra-thin film polymer window. The main filter operates at voltage of $50 \mathrm{kV}$ and current of $100 \mu \mathrm{A}$. The detection window diameter is $8 \mathrm{~mm}$, thus the measurement area per test is approximately $60 \mathrm{~mm}^{2}$. The acquisition time is set to $180 \mathrm{~s}$ for the collection of compositional data, with $60 \mathrm{~s}$ each for Main, High, and Low filters. Ensure that at least three valid readings are obtained from the same part of each sample, and if one of the first three readings shows simultaneous fluctuations in content of multiple elements that are significantly different from the other two readings, the reading is considered invalid and then reanalyzed until at least three valid readings are obtained, the average of which is thereafter accepted as the result of the test area.

A specific problem with pXRF systems is conducting the analysis in an atmosphere which make it difficult to analyze light elements (up to $\mathrm{Ca}$ ), in case of jade, it is silicon, aluminium and magnesium [27]. Equipment manufacturers individually solve this problem by creating calibration techniques oriented to a certain chemical matrix of the sample and the parameters of the device. The result is a deliberately incomparable representation of data on the contents of light elements for different devices, which allows obtaining reproduced data only 
when using one selected analyzer. Therefore, the elements of interest in this study are above Ca.

Here, the Soil mode was selected for it is expected to offer a better scan of trace elements when in a Si matrix [28]. To prepare the data for statistical analysis, some elements with readings consistently below the limit of detection (LOD) of the pXRF analyzer were excluded from further analysis. After the initial data processing, 12 elements were retained for the analyses: sulfur $(\mathrm{S})$, potassium $(\mathrm{K})$, calcium $(\mathrm{Ca})$, titanium $(\mathrm{Ti})$, vanadium $(\mathrm{V}), \mathrm{Cr}$ (Chromium), manganese $(\mathrm{Mn})$, iron $(\mathrm{Fe})$, copper $(\mathrm{Cu})$, zinc $(\mathrm{Zn})$, barium $(\mathrm{Ba})$, mercury $(\mathrm{Hg})$. The detailed data are shown in Additional file 2: Table S2.

According to the previously measured results, mainly based on infrared spectroscopy data, all 112 samples in this study are nephrite $[17,29]$. This allows comparisons between elemental data to be based on the same mineral material.

\section{Results and discussion}

The coefficient of variation

In probability theory and statistics, the Coefficient of Variation $(\mathrm{CV})$ is used as a measure of standardized variability for each element. This was calculated by dividing the standard deviation by the mean for each element of the Yuehe nephrite data set $(n=230)$ (Table 1).When the $\mathrm{CV}$ is low, the data have less variability and higher stability.

For this case, the major element $\mathrm{Ca}$ has the lowest value of $\mathrm{CV}$, which is also in line with the usual perception. The major element content is very large and is itself less influenced by impurity minerals in nephrite and factors in the soil micro-environment. In contrast, the trace element content is not only affected by the surrounding rocks of nephrite, but also causes stronger fluctuations due to intrusive effects of random element in the soil [30]. As expected, the trace elements in the nephrite samples exhibit a significantly higher level of variability than the nephrite major elements. If 1 is set as the cutoff, the elements below this values in the order from smallest to

Table 1 Coefficient of variation for the elements sorted from lowest to highest

\begin{tabular}{llll}
\hline Element & $\begin{array}{l}\text { Coefficient of } \\
\text { variation }\end{array}$ & Element & $\begin{array}{l}\text { Coefficient } \\
\text { of variation }\end{array}$ \\
\hline $\mathrm{S}$ & 1.1340 & $\mathrm{Mn}$ & 0.9607 \\
$\mathrm{~K}$ & 0.7259 & $\mathrm{Fe}$ & 0.8670 \\
$\mathrm{Ca}$ & 0.1497 & $\mathrm{Cu}$ & 1.1666 \\
$\mathrm{Ti}$ & 1.4658 & $\mathrm{Zn}$ & 1.3074 \\
$\mathrm{~V}$ & 0.5408 & $\mathrm{Ba}$ & 0.9454 \\
$\mathrm{Cr}$ & 0.1792 & $\mathrm{Hg}$ & 1.5122 \\
\hline
\end{tabular}

largest are $\mathrm{Ca}, \mathrm{Cr}, \mathrm{V}, \mathrm{K}, \mathrm{Fe}, \mathrm{Mn}$ and $\mathrm{Ba}$. And the elements greater than 1 are $\mathrm{S}, \mathrm{Cu}, \mathrm{Zn}, \mathrm{Ti}$ and $\mathrm{Hg}$. This grouping could correspond to the results of the cluster analysis very well.

\section{Cluster analysis}

Cluster analysis can categorize elements with similar geochemical characteristics, and can identify elements with close performance. Theoretically, a hierarchical R-type cluster analysis of the elements from the pXRF scans (normalized data) can visually represent the degree of similarity in terms of the order of coalescence and the distance between groups. More specifically, in the elemental clustering analysis pedigree chart (by single linkage), the vertical coordinate represents the distance between different variables, and the similarity between variables increases as the distance gets closer (Fig. 4). Back to the current case, the different elemental assemblages correspond to a large extent to the different primary geochemical features and factors such as weathering, erosion and alteration that affected the appearance of nephrite [31].

In Fig. 4, the specificity of $\mathrm{Cu}$ is remarkable, and its distance from other elements is much greater than that between other elements. Apart from $\mathrm{Cu}$, the remaining elements can be roughly divided into two major groups. First, $\mathrm{Ca}, \mathrm{Cr}, \mathrm{V}, \mathrm{K}, \mathrm{Mn}, \mathrm{Fe}$ and $\mathrm{Ba}$ are classified as the same group, which can be considered as elements in the primary and impurity minerals of nephrite [32]. Second, $\mathrm{S}, \mathrm{Hg}, \mathrm{Zn}$ and $\mathrm{Ti}$ are common trace elements in the soil or minerals [32, 33]. As for $\mathrm{Cu}$, the tomb also had a large number of bronzes, where the loss and flow of copper elements would more or less make the copper content of nephrite increase. Certainly the occurrence of elemental exchange (possibly only unidirectional) triggered by the co-placement of bronze and jade deserves further attention.

Moreover, the fact that $\mathrm{S}$ and $\mathrm{Hg}$ are grouped together implies that, in addition to the trace elements of the soil itself, other exogenous elements have intruded into the nephrite. The compound of $\mathrm{S}$ and $\mathrm{Hg}$, cinnabar, is precisely one of the striking features of the Yuehe Tomb No.1, and its large-scale use has caused many red particles still remaining in the decorative grooves of many nephrite objects to this day (such as M1:129, M1:161 and M1:316 in Fig. 3). In general, these three types of clusters reflect both the affinity of geochemical properties among elements, and the regularity of elemental migration and deposition.

\section{Correlation analysis}

Correlation analysis can help to reveal the relevance between elements, and then to identify the possible 


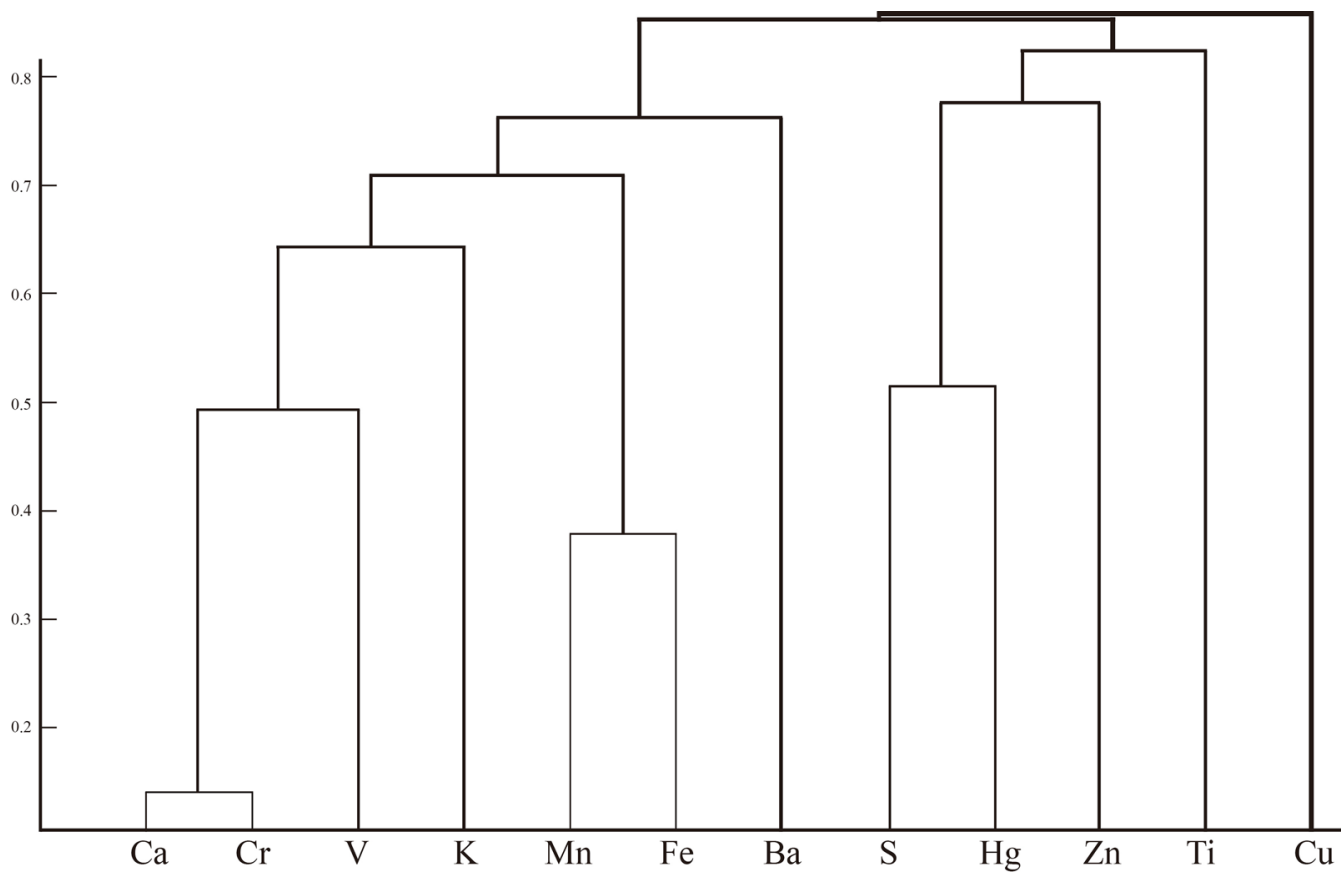

Fig. 4 The pedigree chart of cluster analysis

sources of various elements. The higher the correlation between chemical elements in nephrite, the higher the possibility that the elements come from the same stable input. Therefore, it serves a similar function as cluster analysis, but focuses more on the commonality between elements two by two.

As shown in Table 2, there are three groups of elements with correlation coefficients higher than 0.6 , including $\mathrm{S}$ and $\mathrm{Hg}, \mathrm{Mn}$ and $\mathrm{Fe}$, as well as $\mathrm{Ca}$ and $\mathrm{Cr}$. They are almost the groups whose distance is less than 0.6 in the cluster analysis (in Fig. 4), thus further confirming that the elements within these groups have more similar mode of occurrence. However, the correlation coefficient of $\mathrm{Ca}$ and $\mathrm{Cr}$ is not the largest, although they are the first elements to cluster. The peculiarity is probably due to the fact that $\mathrm{Ca}$ is the major element, although it has a similar geochemical background to some of the common elements in nephrite as displayed in Fig. 4, it is supposed to have stronger correlation reasonably with other major elements, and its correlation to trace elements is relatively less significant [32]. The case of Fe is different. In some sense, Fe is considered a major element since it can

Table 2 Pearson correlation coefficient matrix

\begin{tabular}{|c|c|c|c|c|c|c|c|c|c|c|c|}
\hline & $S$ & $\mathrm{~K}$ & $\mathrm{Ca}$ & $\mathrm{Cr}$ & $\mathrm{Ti}$ & v & $M n$ & $\mathrm{Fe}$ & $\mathrm{Cu}$ & $\mathrm{Zn}$ & $\mathrm{Ba}$ \\
\hline K & 0.1015 & & & & & & & & & & \\
\hline $\mathrm{Ca}$ & -0.3388 & -0.1561 & & & & & & & & & \\
\hline $\mathrm{Cr}$ & -0.1365 & -0.0516 & 0.6307 & & & & & & & & \\
\hline $\mathrm{Ti}$ & 0.0414 & 0.0264 & -0.1709 & 0.1478 & & & & & & & \\
\hline V & -0.0575 & -0.0377 & 0.0703 & 0.1492 & 0.2251 & & & & & & \\
\hline $\mathrm{Mn}$ & 0.1022 & -0.1129 & 0.0338 & 0.0020 & -0.0068 & 0.1453 & & & & & \\
\hline $\mathrm{Fe}$ & 0.1774 & -0.0993 & 0.0039 & -0.0632 & 0.0771 & 0.1565 & 0.8439 & & & & \\
\hline $\mathrm{Cu}$ & 0.2651 & 0.1826 & -0.1960 & -0.0709 & -0.0151 & 0.0233 & -0.0382 & 0.0505 & & & \\
\hline $\mathrm{Zn}$ & 0.4973 & 0.0053 & -0.2753 & 0.0876 & 0.4836 & 0.1431 & 0.1551 & 0.1338 & -0.0254 & & \\
\hline $\mathrm{Ba}$ & 0.0207 & -0.1129 & -0.1091 & -0.1210 & -0.0058 & -0.0630 & 0.1863 & 0.0744 & -0.0283 & 0.1054 & \\
\hline $\mathrm{Hg}$ & 0.8025 & 0.0474 & -0.4252 & -0.3908 & -0.0535 & -0.0511 & 0.1133 & 0.1910 & 0.1189 & 0.4487 & 0.1076 \\
\hline
\end{tabular}


often substitute for Mg, especially if the nephrite is green (serpentine-related genesis). In this batch of samples, the Fe content of most of the tested parts is less than $1 \%$, implying that Fe may be present in the impurity minerals. Inclusions in nephrite are not only magnetite, limonite, pyrite, but also a type of inclusion containing $\mathrm{Fe}-\mathrm{Mn}$ which usually manifests itself as fern-like, which is most likely the source of $\mathrm{Mn}$ [34]. Besides, neither $\mathrm{S}$ nor $\mathrm{Hg}$ is a common element in nephrite inclusions, as can be barely seen from their respective negative correlation coefficients with $\mathrm{Ca}$. Their contents are more than typical trace elements, and the high correlation indicates that they may be bound together in some compound form. And this requires taking into account whether their level is commensurate. Moreover, the nephrite objects from Yuehe Tomb No. 1 appear generally dark in hue, unlike other excavated nephrite, and it is reasonable to wonder if these two elements, not commonly found in other cases, played an important role in this color change.

\section{Elements and secondary colors}

The ancient Chinese also noticed this phenomenon of jade darkening, and they may have imaginatively referred to it as mercury alteration, based on the burial practice of using mercury for embalming. Mercury alteration is unique among the several types of alteration that occur in Chinese ancient jades and often appears on ancient jade artifacts unearthed from high-grade tombs of the preQin period (before 221 BCE) [35]. Previous studies have speculated the similar darkening phenomenon on jade may result from carbon, manganese, iron and copper, but a closer examination of Yuehe jade again links blackening and mercury, and stimulated more intense discussion on the blackening mechanism of ancient jade [33]. Some related simulated experiments have also been conducted and confirmed that the black $\mathrm{HgS}$ was immersed inside the jade, forming a black elemental mercury, rather than the metallic mercury element dipped in the jade or red mercury causing black mercury alteration [36]. Moreover, a recent systematic scientific analysis of these nephrite objects from Yuehe Tomb No. 1 indicate the coloring factor is metacinnabar $(-\mathrm{HgS})$, which might be converted from cinnabar $(-\mathrm{HgS})$ in the influence of bromine and alkali [29].

However, the point that was overlooked before is that the contents of $\mathrm{Hg}$ and $\mathrm{S}$ do not seem to match well into the compound HgS. We make a scatter plot of the data obtained by scanning the black area $(n=109)$, and add a regression line $y=0.25 x+327.46$ (Fig. 5). According to the relative atomic masses of $\mathrm{S}(=32.07)$ and $\mathrm{Hg}$ $(=200.59)$, the ratio between them should be approximately 6.25 based on a 1:1 atomic number combination, which is 25 times different from the actual result. Therefore, it can be assumed that the source of Hg is almost from $\mathrm{HgS}$, but there are other sources of $\mathrm{S}$. The human body (vertebrates) contains about $0.25 \%$ elemental sulfur (plants also contain elemental sulfur, but less than animals), the slow decay of the body in the sealed burial environment of the tomb releasing sulfur (or hydrogen sulfide) in the process [36]. It is suggested that the close

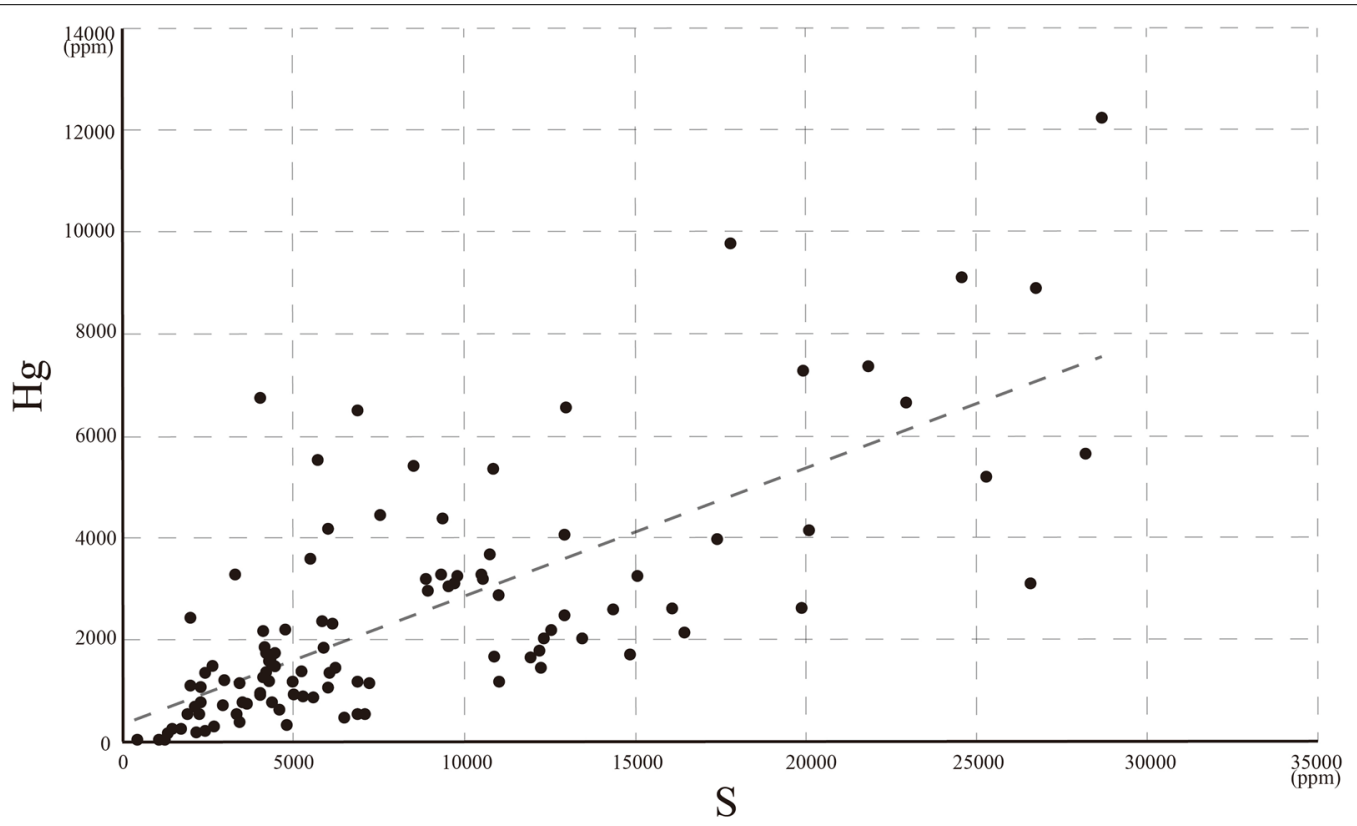

Fig. 5 The scatter plot of S vs. $\mathrm{Hg}(\mathrm{ppm})$ 
or even direct contact between jade and body will make it easy for $\mathrm{S}$ to seep inside the jade [36]. Hence, there is also the view that the cause of black $\mathrm{HgS}$ is the combination of sulfur (or hydrogen sulfide) and mercury [36]. The sever imbalanced content between $\mathrm{Hg}$ and $\mathrm{S}$ also serve as a reminder that the current study about mercury alteration could not reach a definitive conclusion.

Although the Ca content range of this batch of data is $3.7-13.6 \%$, most of the nephrite is fairly stable in terms of $\mathrm{Ca}$ at different tested points. This can only demonstrate that the purity of the tremolite component in some of these nephrite samples is not very good. However, there are still some nephrite pieces that have been affected by weathering, which led to obvious changes in the Ca content of some parts. There is an early claim that the whitening of jade is related to the increase in Ca content, and this has been referred to as calcification [37]. Microscopic observation on the whitening parts shows no significant change in the thickness of the crystal fibers of the constituent minerals, but there is a tendency for the structure to loosen, thus turning from translucent to opaque and fading to white [38]. Then many studies have since shown that $\mathrm{Ca}$ is actually lost due to qualitative changes, thus some scholars urged the elimination of the concept of calcification [38]. But recent research have revised these views, suggesting that the 'calcification' of the jade whitening actually occurs, usually in neutral and alkaline environments, where the soil $\mathrm{pH}$ is closely related to different calcium salts $\left[\mathrm{CaCO}_{3}\right.$ or $\mathrm{Ca}\left(\mathrm{HCO}_{3}\right)_{2}$, etc.]. The deposition process of calcium salts is relatively easy while the penetrating is comparatively hard, which makes this calcification phenomenon rare and the whitening mostly appears as a dotted distribution [38].

To determine the whitening mechanism of Yuehe nephrite, we plotted the Ca content of whitening nephrite in the white and non-white regions for comparison $(\mathrm{n}=16)$ (Fig. 6). The majority of cases show an approximate $10-20 \%$ increased Ca content in the whitening part of the nephrite. This is also confirms the rationality of the so-called calcification. In addition, although they are all in a relatively uniform soil micro-environment, there are still 4 samples showing varying weathering performance with a decreased Ca percentage, which probably implies different whitening mechanisms. Most previous studies have been conducted on individual samples [9, 37], with little analysis of the overall condition of jade excavated from a certain site, to the extent that regular insights may have been missed. The relationship between this notidentical deviation of $\mathrm{Ca}$ and jade whitening deserves further study.

\section{Combined with cultural factors}

As a class of objects made of precious materials, many nephrite artifacts do not appear individually, but in combinations. Examples include the six auspicious jade implements mentioned earlier and complicated hangings consisting of a number of pedants, ornaments and tubes. On the other hand, some jade pieces are used in pairs due to the aesthetic need for symmetry, which has resulted in twin objects with extremely similar appearance (in terms

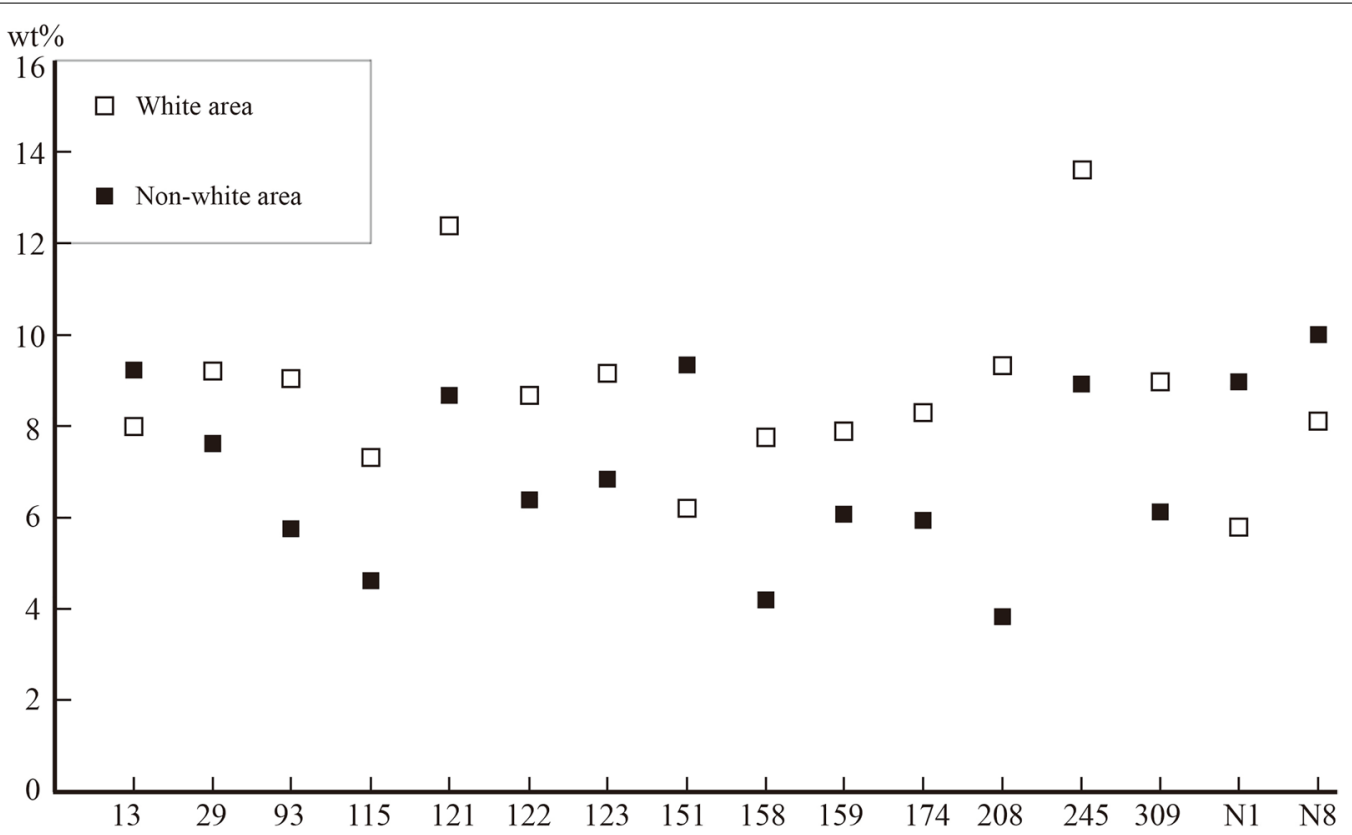

Fig. 6 The Ca content of partially whitening nephrite (the data of non-white areas are average values) 
of shape, material, decoration, engraving technique, etc.). It is interesting to note that these twin artifacts may take on a completely different color after being buried in the soil for thousands of years. Various cultural sources of twin samples are available among Yuehe nephrite (Table 3). They provide a case for examining such different secondary variations on almost the same material.

In order to present the similarities and differences of these twin nephrite artifacts in a more integrated way, a principal component analysis was performed on a total of 57 data from 27 samples (see Additional file 3: Table S3

Table 3 Nephrite pieces with extremely similar appearance

\begin{tabular}{ll}
\hline Type & Sample No \\
\hline Dongyi style bird pendant & M1:78, M1:259 \\
Chu style oblong pendant & M1:100, M1:318 \\
Yue style Jue & M1:265, M1:399 \\
Wu style oblong pendant & M1:129, M1:164 \\
Tiger & M1:79, M1:346, M1:357 \\
Flake ornament A & M1:162(2), M1:185, M1:186, M1:391 \\
Flake ornament B & M1:159, M1:174 \\
Animal ornament & M1:161, M1:347 \\
Triangular ornament & M1:208, M1:247, M1:397 \\
Gui & M1:N18, M1:N21 \\
Tube & M1:13, M1:N8, M1:N10 \\
\hline
\end{tabular}

for details). All 11 elements were included in the statistics, as this allowed for a comprehensive representation of the native properties and weathering conditions of each sample. The results are displayed in Fig. 7. The cumulative explained variance ratio is not very satisfactory, and these two principal components only occupy $50 \%$ of the contribution, which can barely reflect the potential information of the data. Some types of nephrite samples are more concentrated in distribution, or even independently grouped, such as Animal ornament, Flake ornament B and Yue style artifacts. Even under the influence of weathering and alteration, some nephrite pieces still have common properties.

Examining these samples with regional styles, they almost do not intersect individually, which seemingly suggests somewhat a discernible provenance for the nephrite material. On the contrary, there is a remarkable variation within each group, especially the Dongyi and Chu group, making it difficult to characterize the geochemical elements within a certain range. Many previous analyses of ancient jade (almost exclusively nondestructive) have discussed the issue of distinguishing provenance by elements [39]. They are difficult to exclude visually indistinguishable elemental variation in the jade caused by secondary changes. However, most cases in Fig. 7 still show significant differences between samples of the same nephrite material at different test points (see Additional file 3: Table S3). Some of the test

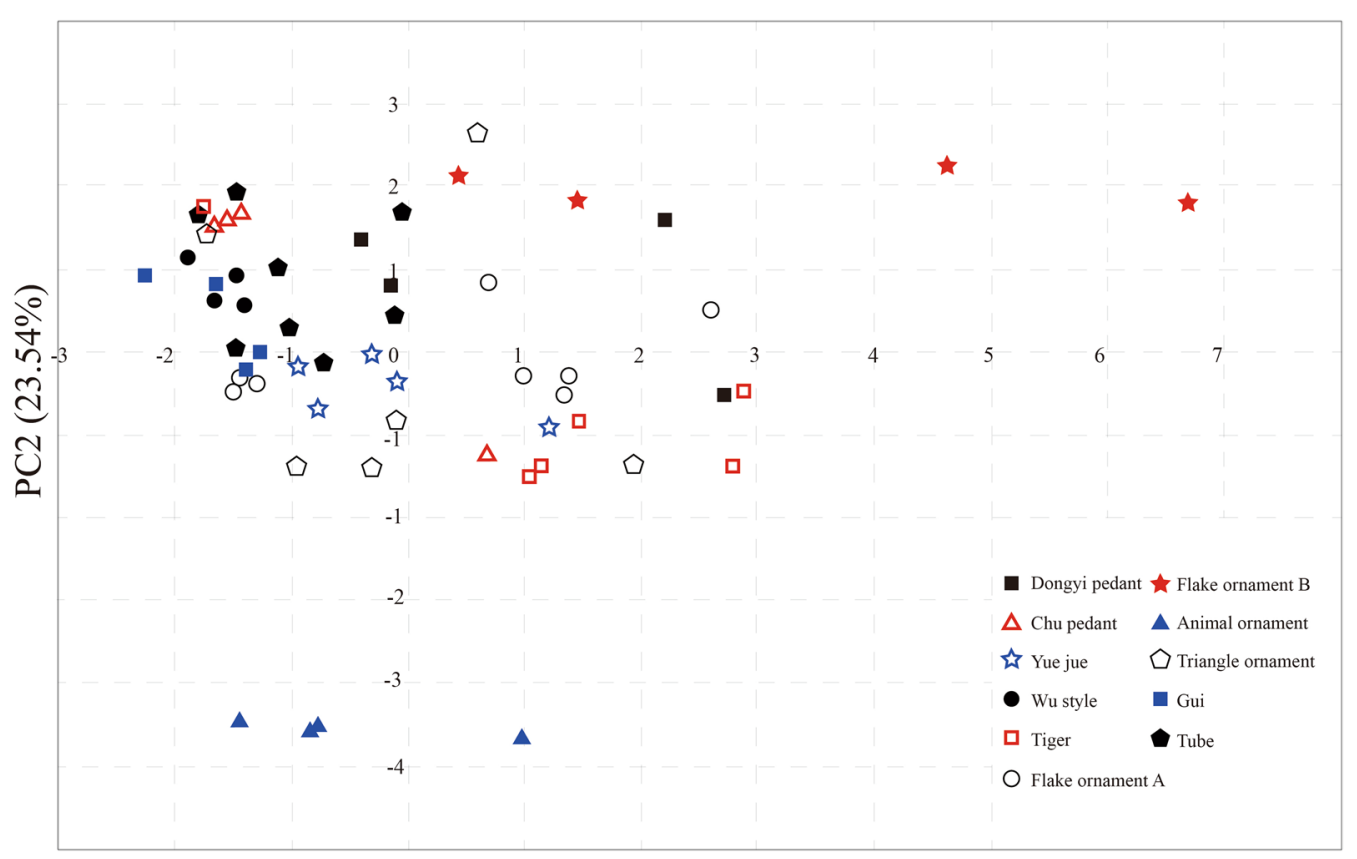

PC1 $(26.43 \%)$

Fig. 7 The principal component analysis scatter plot of twin nephrite artifacts (Details of the legend are shown in Table 3) 
points actually have almost the same hue and other sensory effects. This hints at a very important point in the detection of ancient jade, where visual similarities may in fact contain differences in the elements. This situation reminds of the risk to reveal the geochemical characteristics of ancient jade materials purely from the perspective of the elements. Previous practice could only compare these elemental data with known deposits of nephrite, and tend to seek sources in the neighboring geography of the corresponding territory according to cultural factors [39]. This is rather reckless when nephrite deposits of comparable quality to ancient jade had not yet been identified in the Central Plains (see Fig. 1). Only by clarifying the specific mechanisms of secondary changes can we understand the elemental indicators that represent the ancient jade itself, and thus further discriminate the provenance of the jade material.

\section{Conclusions}

A total of 112 pieces of nephrite artifacts unearthed from the Yuehe tomb No.1 were carefully been tested by pXRF analysis in this study and 230 data were obtained. The regular recognition of ancient nephrite artifacts that were previously missed due to small sample size or low precision can be confirmed from the large-scale data.

The assemblages of different elements derived from cluster analysis can match the values of coefficient of variation and correlation coefficient. The results can also roughly correspond to the main sources of the elements. The relevant findings also imply that the higher content of $\mathrm{S}$ and $\mathrm{Hg}$ may have caused the difference in color from other excavated nephrite. But the imbalance in its content, specifically too much $\mathrm{S}$ compared to $\mathrm{Hg}$, also serve as a reminder that the current study about mercury alteration could not reach a definitive conclusion. For another secondary change resulting in whitening, a comparative study of the white and non-white regions of some nephrite samples show a general increase in Ca content, which confirm the previously refuted view of calcification. Unlike in the past, these data were not used to make inferences about the provenance of the nephrite material. Conversely, the twin nephrite artifacts with extremely similar appearance were selected for principal component analysis to demonstrate that elements actually also changed in places where they did not visually differ. It is not reasonable to use these data for provenance speculation when the weathering mechanism is not fully understood.

\section{Supplementary Information}

The online version contains supplementary material available at https://doi. org/10.1186/s40494-021-00642-w.

Additional file 1: Table S1. Information sheet of nephrite objects (Some samples have a dark/black color on the glossy surface due to excessive reflection).

Additional file 2: Table S2. Portable XRF results of chemical composition of the nephrite artifacts from the Tomb No.1, Yuehe Town.

Additional file 3: Table S3. Principal component analysis results of nephrite pieces with extremely similar appearance.

\section{Acknowledgements}

We would like to thank Mr. Yifeng Lou for his help in the experiment. We are grateful to anonymous reviewers whose comments greatly improved the quality of the manuscript.

\section{Authors' contributions}

$D C, Y Y$ and WL performed the data analysis and were major contributors in writing the manuscript. JL helped the data collecting. BQ provided the archaeological context. All authors read and approved the final manuscript.

\section{Funding}

This research is Supported by the National Social Science Foundation of China (Grant No. 20VJXG018), Beijing Municipal Social Science Foundation (Grant No. 21DTR046), the Fundamental Research Funds for the Central Universities.

Availability of data and materials

All data generated or analyzed during this study are included in this published article.

\section{Declarations}

\section{Competing interests}

We declare that we have no financial and personal relationships with other people or organizations that can inappropriately influence our work, there is no professional or other personal interest of any nature or kind in any product, service and/or company that could be construed as influencing the position presented in, or the review of, the manuscript entitled.

\section{Author details}

${ }^{1}$ Department of Archaeology and Anthropology, University of Chinese Academy of Sciences, Beijing 100049, China. ${ }^{2}$ Key Laboratory of Vertebrate Evolution and Human Origin, Chinese Academy of Sciences, Institute of Vertebrate Paleontology and Paleoanthropology, Beijing 100049, China. ${ }^{3}$ Institute of Cultural Relic Research of Nanyang City, Nanyang 473000, Henan, China.

Received: 5 November 2021 Accepted: 28 December 2021

Published online: 08 January 2022

\author{
References \\ 1. Yang BD. The plate tectonics of Chinese prehistoric jade cultures. \\ Palace Mus J. 2005;4:6-24 (in Chinese). \\ 2. Wen $G$, Jing Z. Mineralogical studies of Chinese archaic Jade. Acta Geol \\ Taiwan. 1996;32:55-83. \\ 3. Barnes G. Understanding Chinese jade in a world context. J Br Acad. \\ 2018;6:1-63.
}


4. Tang C, Tang MH, Liu GX, Wen TD. The Neolithic Jade revolution in Northeast China. In: Childs-Johnson E, editor. The Oxford handbook of early China. Oxford: Oxford University Press; 2021. p. 73-100.

5. Kienholz M. The Characterisation of Pounamu Sources in New Zealand Using PXRF. The University of Auckland, master thesis; 2014.

6. Jiang Y, Shi G, Xu L, Li X. Mineralogy and geochemistry of nephrite jade from Yinggelike Deposit, Altyn Tagh (Xinjiang, NW China). Minerals. 2020;10:418.

7. Hawthorne FC, Oberti R, Harlow GE, et al. Nomenclature of the amphibole supergroup. Am Miner. 2012;97:2031-48.

8. Lu L, Bian ZH, Wang F, Wei JQ, Ran XH. Comparative study on mineral components, microstructures and appearance characteristics of nephrite from different origins. J Gems Gemmol. 2014;16(2):56-64.

9. Zhang C, Yu XY, Jiang TL. Mineral association and graphite inclusions in nephrite jade from Liaoning, northeast China: implications for metamorphic conditions and ore genesis. Geosci Front. 2019;10(2):425-37.

10. Zhang C, Yu XY, Yang F, Santosh M, Huo D. Petrology and geochronology of the Yushigou nephrite jade from the North Qilian Orogen, NW China: implications for subduction-related processes. Lithos. 2020. https://doi. org/10.1016/j.lithos.2020.105894.

11. Zhao HX, Li QH, Liu S, Hu YQ, Gan FX. Nondestructive analysis of Jade artifacts from the cemetery of the Ying state in Henan province, china using confocal Raman microspectroscopy and portable X-ray fluorescence spectroscopy. J Raman Spectrosc. 2014;45(2):173-8.

12. Zhang $B$, Wu $X$, Sun $Y$, et al. Complex raw materials and supply system: mineralogical and geochemical study for the Jade Artefacts of Longshan Culture (2400-2000BC) from Sujiacun Site in Coastal Shandong, China. Archaeometry. 2021;63(1):1-18.

13. Douglas JG. Exploring issues of geological source for jade worked by ancient Chinese cultures with the aid of X-ray fluorescence spectroscopy. In: Scientific Research in the Field of Asian Art, pp. 192-199; 2003

14. Zhang ZW, Gan FX, Cheng HS. PIXE analysis of nephrite minerals from different deposits. Nucl Instrum Methods Phys Res Sect B. 2011;269(4):460-5.

15. Kostov Rl, Protochristov C, Stoyanov C, et al. Micro-PIXE geochemical fingerprinting of nephrite neolithic artifacts from Southwest Bulgaria. Geoarchaeology. 2012;27:1-13.

16. Tsydenova N, Morozov MV, Rampilova MV, et al. Chemical and spectroscopic study of nephrite artifacts from transbaikalia, Russia: geological sources and possible transportation routes. Quatern Int 2015;355(12):114-25.

17. Du JP. Study of the jade excavated from the Spring and Autumn Tomb of Yuehe in Tongbai. Beijing: Science Press; 2018. (in Chinese).

18. ICRRNC (Institute of Cultural Relic Research of Nanyang City). Excavation brief of Spring and Autumn Tomb No. 1 in Yuehe. Tongbai Cult Relics Central China. 1997:4:8-23 (in Chinese)

19. Yu YX. A preliminary study of bronze tombs in spring and Autumn Period in Nanyang Basin. Zhengzhou: Zhengzhou University; 2017.

20. Jin RQ. A study of the bronzes and the history of the Yang state. Acad J Zhongzhou. 2011;2:167-70 (in Chinese).

21. Li C. Research on jade culture of prehistoric age, the Three Dynasties, Qin and Han dynasties. PhD Thesis, Shandong University; 2011. (in Chinese with English abstract)

22. Tang QC, Wu YW. Body and etiquette: practicing propriety by wearing Jade and the origin of confucian myth-ritual. J Lit Art Stud. 2017;7(4):399-409.

23. Hansford $\mathrm{SH}$. The disposition of ritual jades in royal burials of the Chou dynasty. J R Asiat Soc Great Br Ireland. 1949;2:138-42.

24. Wang Q. Study of the jade remains excavated from the Shang, Zhou and Western Han tombs in the southern part of Henan. Cult Relics Central China. 2017;1:43-58 (in Chinese).

25. Shi RC. Jades of Yuehe No. 1 Tomb and cultural exchanges in Eastern Zhou. Southeast Cult. 2010;5:71-7 (in Chinese).

26. Yang XK. Study of Wu and Yue Style Jade. PhD Thesis, Fudan University; 2011. (in Chinese).

27. Alkin S, Morozov M, Zotkina L. Nephrite in the archaeology of Northern and Central Asia: New approaches to the interdisciplinary research of the problem of contacts between civilizations, 54-64. The annual international academic conference of IASS 2017. Ho Chi Minh City: Vietnam National University; 2017.
28. Yang $Y$, Tong $X$, Zhang $Y$. Spatial variability of soil properties and portable $X$-ray fluorescence-quantified elements of typical golf courses soils. Sci Rep. 2020;10:519. https://doi.org/10.1038/s41598-020-57430-y.

29. Mai YY, Wang R, Cui H. Study on the blackening mechanism of buried cinnabar within ancient Chinese jades. J Cult Herit. 2021:49(4):164-73.

30. Campbell GP, Miskelly GM, Coulson SA, et al. Elemental analysis of New Zealand Nephrite Jade (pounamu) for forensic purposes. UdG Digital Repository: Universitat de Girona; 2008.

31. Wang R, Zhang WS. Application of Raman spectroscopy in the nondestructive analyses of ancient Chinese Jades. J Raman Spectrosc. 2011;42(6):1324-9.

32. Liu S, Su BM, Li QH, et al. Application of calibration curve method and partial least squares regression analysis to quantitative analysis of nephrite samples using XRF. Spectrosc Spectral Anal. 2015;35:245-51 (in Chinese with English abstract).

33. Xu L, Wang JX. Analysis of the blackening of mercury osmosis phenomenon of ancient nephrite-an Example of nephrite dated back to Spring and Autumn era excavated in No.1 Tomb, Yuehe Town, Tongbai County, Nanyang, China. Proceedings of the 2017 China International Jewelry Academic Exchange Conference; 2017

34. Qiu ZL. The concept of inclusions in jade, its classification and its indication of origin. Proceedings of the 2011 China International Jewelry Academic Exchange Conference; 2011.

35. Bao Y, Xu C, Zhu Q, et al. A study on Chinese ancient jades with mercury alteration unearthed from Lizhou'ao Tomb. Sci Rep. 2019;9:19849. https:// doi.org/10.1038/s41598-019-55138-2.

36. Zhao RT, Yu P, Shao F, et al. Another study on the black impregnation phenomena called "mercury seeps" in some jades unearthed from the Tombs of Chu Region Hunan in Warring States Period. Museum. 2020;20(2):98-102.

37. Gong MT, Rong W, Cheng HS. Preliminary study on the impact of relative humidity on the conservation of jades. Stud Conserv. 2013;58(2):88-94.

38. Wang R, Tang JG, He YL, Wang CS. Study on the phenomenon of natural albinism of Jades with tremolite and serpentine in Yin Ruins-study on the phenomenon of natural albinism of Jades with Tremolite and serpentine in Yin Ruins. Cult Relics Southern China. 2018;3:79-87 (in Chinese).

39. Wang R. Progress review of the scientific study of Chinese ancient jade. Archaeometry. 2011:53(4):674-92.

\section{Publisher's Note}

Springer Nature remains neutral with regard to jurisdictional claims in published maps and institutional affiliations.

\section{Submit your manuscript to a SpringerOpen ${ }^{\circ}$ journal and benefit from:}

- Convenient online submission

- Rigorous peer review

- Open access: articles freely available online

- High visibility within the field

Retaining the copyright to your article

Submit your next manuscript at springeropen.com 